\title{
Embryonic Thermal Manipulation and in ovo Gamma-Aminobutyric Acid Supplementation Regulating the Chick Weight and Stress-Related Genes at Hatch
}

\section{OPEN ACCESS}

Edited by:

Minoru Tanaka,

Nippon Veterinary and Life Science

University, Japan

Reviewed by:

Aleksandra Dunislawska,

University of Science and Technology

(UTP), Poland

Djoni Prawira Rahardja

Hasanuddin University, Indonesia

*Correspondence:

Yang-Ho Cho

yhchoi@gnu.ac.kr

†These authors have contributed equally to this work

Specialty section:

This article was submitted to Animal Nutrition and Metabolism,

a section of the journal

Frontiers in Veterinary Science

Received: 02 November 2021 Accepted: 03 December 2021

Published: 07 January 2022

Citation:

Goel A, Ncho CM, Jeong C-M and Choi Y-H (2022) Embryonic Thermal

Manipulation and in ovo

Gamma-Aminobutyric Acid

Supplementation Regulating the Chick Weight and Stress-Related Genes at Hatch. Front. Vet. Sci. 8:807450. doi: 10.3389/fvets.2021.807450

\begin{abstract}
Akshat Goel ${ }^{1,2 \dagger}$, Chris Major Ncho ${ }^{1,2 \dagger}$, Chae-Mi Jeong ${ }^{2,3}$ and Yang-Ho Choi ${ }^{1,2,3 *}$
${ }^{1}$ Department of Animal Science, Gyeongsang National University, Jinju, South Korea, ${ }^{2}$ Institute of Agriculture and Life Sciences, Gyeongsang National University, Jinju, South Korea, ${ }^{3}$ Division of Applied Life Sciences (BK21 Plus Program), Gyeongsang National University, Jinju, South Korea
\end{abstract}

Chickens are exposed to numerous types of stress from hatching to shipping, influencing poultry production. Embryonic manipulation may develop resistance against several stressors. This study investigates the effects of thermoneutral temperature $\left(\mathrm{TO} ; 37.8^{\circ} \mathrm{C}\right)$ with no injection (NO) (TONO), TO with $0.6 \mathrm{ml}$ of $10 \%$ in ovo gamma-aminobutyric acid (GABA) supplementation (N1) at 17.5th embryonic day (ED) (TON1), thermal manipulation (T1) at $39.6^{\circ} \mathrm{C}$ from the 10 th to 18th ED (6 h/day) with NO (T1NO), and T1 with N1 (T1N1) on hatchability parameters and hepatic expression of stress-related genes in day-old Arbor Acres chicks. The parameters determined were hatchability, body weight (BW), organ weight, hepatic malondialdehyde (MDA), and antioxidant-related gene expression. Percent hatchability was calculated on a fertile egg basis. Growth performance was analyzed using each chick as an experimental unit. Eight birds per group were used for organ weight. Two-way ANOVA was used taking temperature and GABA as the main effect for growth performance and gene expression studies. Analysis was performed using an IBM SPSS statistics software package 25.0 (IBM software, Chicago, IL, USA). Hatchability was similar in all the groups and was slightly lower in the T1N1. Higher BW was recorded in both $\mathrm{T} 1$ and $\mathrm{N} 1$. Intestinal weight and MDA were higher in TON1 against TONO and T1N1, respectively. The expression of HSP70, HSP90, NOX1, and NOX4 genes was higher and SOD and CAT genes were lower in the T1 group. The present results show that $\mathrm{T} 1$ and $\mathrm{N} 1$ independently improve the $\mathrm{BW}$ of broiler chicks at hatch, but T1 strongly regulates stress-related gene expression and suggests that both $\mathrm{T} 1$ and $\mathrm{N} 1$ during incubation can improve performance and alleviate stress after hatch.

Keywords: embryo manipulation, hatchability characteristics, antioxidant, genes, chickens

\section{INTRODUCTION}

Chicken producers face numerous stressful conditions that include high ambient temperature, transportation, delayed feeding, infection, noise, and stocking density (1-3). All these conditions collectively or individually may lead to the generation of reactive oxygen species (ROS). Antioxidants react to counter the ROS generation along with the heat shock proteins (HSPs), the marker for identifying stress (1). 
Previous studies have shown increment in ROS, antioxidants, HSPs, and MDA under heat stress conditions $(4,5)$. Evaluation of these genes may help identify the intensity of stress and the preparation of chickens to withstand stress. Furthermore, manipulation of chicken embryos either by tweaking temperature or feeding supplements may develop tolerance to heat stress during the rearing period.

A continuous decrease in the marketable age of broilers has enhanced the importance of embryonic life (6). Embryonic thermal manipulation (ETM), a method of changing the egg's incubation temperature, has been tested to overcome harmful conditions during environmental stress (7). Similarly, in ovo feeding, a method of administering nutrients or bioactive substances into the eggs during incubation has been attempted to reduce the dreadful effects of stress associated with transportation and delayed feeding $(2,8)$. Although embryonic manipulation has been performed for a few limited aspects, it also has the potential to reduce the negative effects of other stressful conditions. Few studies have shown that ETM can be effective to improve growth performance by increasing body weight at market age $(6,9)$. Most of the studies evaluated the effect of ETM during the later stages of broilers' life during the rearing phase $(7,10)$. However, scanty information is available on the role of ETM in modulating hatchability performance and on its mechanism to develop stress tolerance in chicks at hatch.

Gamma-aminobutyric acid (GABA) as a feed additive or feeding in ovo has shown some potential to overcome stress in chickens (11-14). GABA is a four-carbon non-protein amino acid that acts as an inhibitory neurotransmitter in the central nervous system (15). Other than controlling neuronal excitability, the receptors of GABA were also observed in the liver, pancreas, and kidney (16). Previous studies have reported beneficial effects of dietary supplementation of GABA in laying hens and broiler chickens reared during summer conditions or under heat stress (17-19). Although in ovo feeding has been previously shown to be effective in increasing chicken performance and immune functions $(8,20)$, it is not yet clear whether or not in ovo administration of GABA is beneficial for improving the hatchability status of chicks. Moreover, it is uncertain whether or not ETM along with in ovo GABA injections could synergistically influence hatchability performances without any adverse effects.

The present study was designed to investigate the effect of ETM, GABA supplementation, or their combination on hatching performance and expression of stress-related genes in newly hatched chicks.

\section{MATERIALS AND METHODS}

All the experimental procedures for this study were approved by the Institutional Animal Care and Use Committee of Gyeongsang National University GNU-200916-C0058.

\section{Incubation and in ovo Feeding Procedure}

A total of 280 eggs, obtained from a local Arbor Acres breeder farm (Hapcheon, Korea), were used for this study. The age of the broiler breeder birds was around 30 weeks.
Each egg was weighed using weighing balance (PB4002-S/FACT, Mettler Toledo, Switzerland) with $0.01 \mathrm{~g}$ accuracy, marked, and then incubated in two incubators (Maru 190, Rcom, South Korea) at $37.8^{\circ} \mathrm{C}$ and $56 \%$ relative humidity $(\mathrm{RH})$, and turned automatically once an hour. At 10th embryonic day, the eggs were candled individually (Candler 200, Rcom, South Korea) and those without embryos were removed from the incubator. The remaining eggs were randomly assigned to one of four groups, with similar mean egg weight $(59.6 \pm 0.16 \mathrm{~g})$ and number. Two groups were used for normal temperature (T0) at $37.8^{\circ} \mathrm{C}$ and the other two for thermal manipulation (T1) at $39.6^{\circ} \mathrm{C}$. All the eggs were kept in the incubator that was maintained at $37.8^{\circ} \mathrm{C}$ and only eggs belonging to $\mathrm{T} 1$ group were shifted to the incubator maintained at $39.6^{\circ} \mathrm{C}$ for $6 \mathrm{~h}$ daily from 10:00 a.m. to 4:00 p.m. For each treatment group, one was untreated (N0) and the other was administered intraovally with $10 \%$ GABA (N1). So, there were 4 treatment groups: T0N0; T0N1; T1N0; and T1N1. After candling, T0N0 had 62 eggs while the rest three treatment groups had 63 eggs each. The eggs for T0 and T1 were kept in two separate incubators (Figure 1). The only difference between the two incubators was that the temperature of the incubator with T1 eggs was increased to $39.6^{\circ} \mathrm{C}$ from 10 th $\mathrm{ED}$ to 18 th $\mathrm{ED}$ for $6 \mathrm{~h}$ daily. The selection of GABA dosage for in ovo injections was based on our previous studies (12). In the same study, there were no differences in hatchability characteristics between the in ovo water-injected group and the non-injected control. So, we did not include a water-injected group in the current study. The selection of temperature $\left(39.6^{\circ} \mathrm{C}\right.$ ) and time ( $6 \mathrm{~h}$ a day) for ETM during incubation was done based on a previous study (21).

Three hours before injection, 10\% GABA (Cat. No. A2129, Sigma-Aldrich Inc., St. Louis, MO, USA) solution was prepared in distilled water and stored at $30^{\circ} \mathrm{C}$ until use. The selection of day for in ovo injection was based on a previous study (22). At 17.5 th $\mathrm{ED}$, the eggs for $\mathrm{T} 0$ and $\mathrm{T} 1$ received in ovo injections of $0.6 \mathrm{ml}$ of $10 \% \mathrm{GABA}$ solution from the blunt end of the egg (Figure 1). At first, in ovo injection was carried out in T0N1, followed by $\mathrm{T} 1 \mathrm{~N} 1$. The time taken for in ovo injection procedure was minimized to 5-7 min for each tray. The un-injected control eggs were also removed from the incubator for the same time period to provide similar conditions to all the treatments. All of the eggs were surface-sterilized using $70 \%$ alcohol before drilling the broad end (Figure 2). A $1 \mathrm{ml}$ sterile hypodermic syringe with a 1-inch 23-gauge needle (Kovax-syringe ${ }^{\circledR}$ Korea Vaccine Co., Ltd. Seoul, Korea) was used for each in ovo injection to target the amniotic fluid. The eggs were then sealed with surgical tape $\left(3 \mathrm{M}^{\mathrm{TM}}\right.$ Micropore $^{\mathrm{TM}}$, Saint Paul, Minnesota) and returned to the incubators. The eggs then remained in the incubator until the day of hatch. During the last 3 days of the incubation, both incubators were kept at $36.8^{\circ} \mathrm{C}$ temperature and $70 \% \mathrm{RH}$.

\section{Tissues Sampling}

At the time of hatch, each chick was individually weighed, and eight chicks from each group were randomly chosen, and humanly euthanized using carbon dioxide. The weight of selected organs was recorded and expressed as a percent to BW. Liver tissues $(n=6)$ were collected and snap-frozen in liquid nitrogen for the determination of malondialdehyde (MDA) and gene 


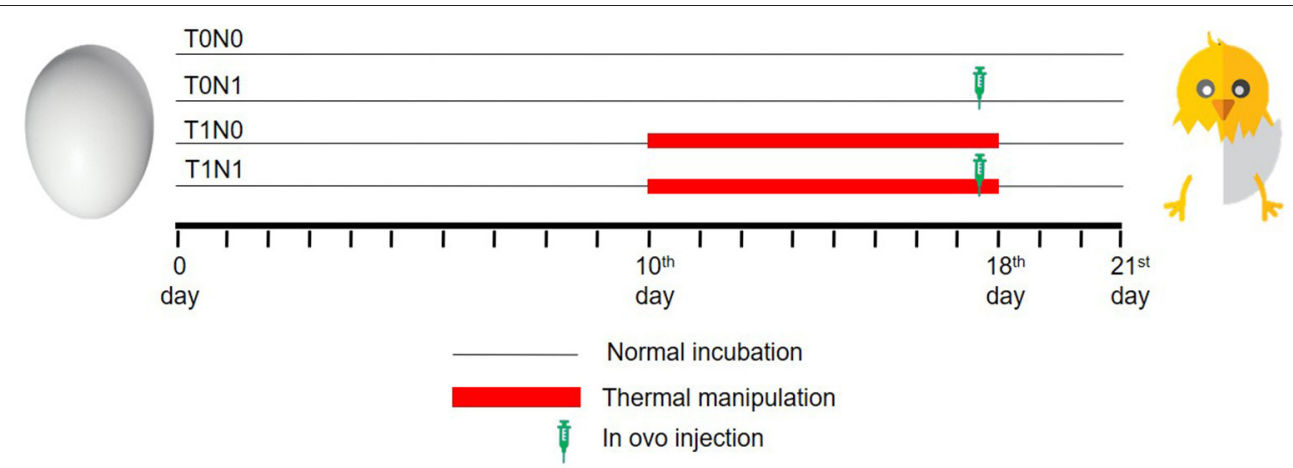

FIGURE 1 | Experimental design showing thermal manipulation duration and in ovo feeding time during incubation. TO: Normal temperature; T1: thermal manipulation; N0: No in ovo injection; N1: in ovo GABA injection.

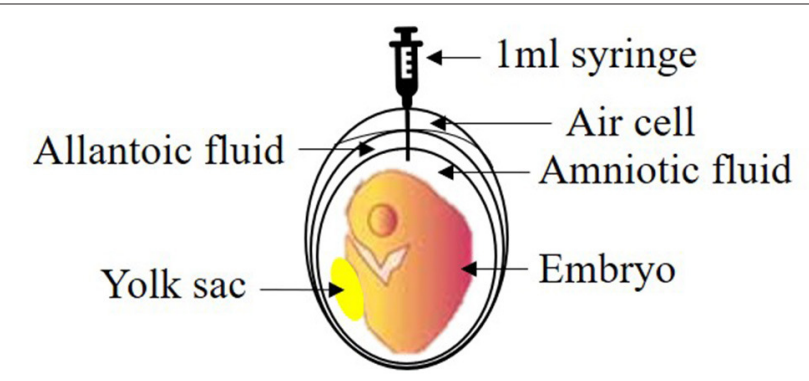

FIGURE 2 | Estimated injection site in the chicken egg at 17.5th ED.

expression. The selection of the liver tissue for evaluating the stress and antioxidant-related genes was based on the previous studies $(7,12)$.

MDA, a marker of oxidative stress, was measured by using the methods $(23,24)$ with some modifications. Briefly, $100 \mathrm{mg}$ liver samples were homogenized in $1 \mathrm{ml}$ of cold $100 \mathrm{mM}$ Tris buffer, $\mathrm{pH} 7.4(1: 10 \mathrm{w} / \mathrm{v})$, and centrifuged at $1000 \times \mathrm{g}$ for $10 \mathrm{~min}$. After separation, one part of the supernatant was added to one part of $40 \%$ trichloroacetic acid (TCA) and 2 parts of $0.67 \%$ thiobarbituric acid (TBA), which was placed at $95^{\circ} \mathrm{C}$ for $45 \mathrm{~min}$ on a water bath. The samples were then removed from the hot water bath and placed on ice-cold water and then centrifuged at $9950 \times \mathrm{g}$ for $30 \mathrm{~s}$ to record supernatant absorbance at $530 \mathrm{~nm}$.

\section{Real-Time PCR for mRNA Quantification}

RNA was extracted from $50 \mathrm{mg}$ liver tissue using Trizol ${ }^{\mathrm{TM}}$ reagent (Thermo Fisher Scientific, Waltham, MA, USA) following the manufacturer's instructions. The concentrations and purities of RNA samples were determined spectrophotometrically using a Nanodrop (Thermo Scientific, Waltham, MA, USA). Subsequently, $2 \mu \mathrm{g}$ of each RNA sample were used for the synthesis of cDNA using the PrimeScript ${ }^{\mathrm{TM}}$ first-strand cDNA synthesis kit (Takara, Tokyo, Japan) following the manufacturer's instructions. The cDNA thus produced was used as a template for the amplification of different genes using real-time polymerase chain reaction (RT-PCR).
TABLE 1 | Primer sequences used to evaluate the hepatic gene expression on the day of hatch.

\begin{tabular}{|c|c|c|c|}
\hline Gene 1 & Sequence & Accession number & References \\
\hline \multirow[t]{2}{*}{ HSP70 } & F: GCTGAACAAGAGCATCAATCCA & AY143693.1 & (25) \\
\hline & R: CAGGAGCAGATCTTGCACATIT & & \\
\hline \multirow[t]{2}{*}{ HSP90 } & F: CCCGAGCAAGCTGGATTCT & NM_001109785 & (25) \\
\hline & R: GGTCATCCCTATGCCGGTATC & & \\
\hline \multirow[t]{2}{*}{ NOX1 } & F: GCGAAGACGTGTTCCTGTAT & NM_0011018301 & (5) \\
\hline & R: GAACCTGTACCAGATGGACTTC & & \\
\hline \multirow[t]{2}{*}{ NOX4 } & F: CCTCTGTGCTTGTACTGTGTAG & NM_001101829.1 & (5) \\
\hline & R: GACATTGGAGGGATGGCTTAT & & \\
\hline \multirow[t]{2}{*}{ SOD } & F: AGGGGGTCATCCACTTCC & NM_205064.1 & (26) \\
\hline & R: CCCATTTGTGTTGTCTCCAA & & \\
\hline \multirow[t]{2}{*}{ CAT } & F: ACCAAGTACTGCAAGGCGAA & NM_001031215.1 & (26) \\
\hline & R: TGAGGGTTCCTCTTCTGGCT & & \\
\hline \multirow[t]{2}{*}{ GAPDH } & F: TTGGCATTGTGGAGGGTCTTA & NM_204305.1 & (25) \\
\hline & R: GTGGACGCTGGGATGATGTT & & \\
\hline
\end{tabular}

HSP70, heat shock protein 70; HSP90, heat shock protein 90; NOX1, nicotinamide adenine dinucleotide phosphate oxidase 1; NOX4, nicotinamide adenine dinucleotide phosphate oxidase 4; SOD, Superoxide dismutase; CAT, Catalase; GAPDH, glyceraldehyde-3-phosphate dehydrogenase.

The amplification of stress and antioxidant-related genes was carried out in StepOnePlus ${ }^{\mathrm{TM}}$ real-time PCR systems (Life Technologies, CA, USA). Each reaction consists of a $20 \mu \mathrm{l}$ containing $10 \mu \mathrm{l}$ Power SYBRTM green PCR master mix (Life Technologies, CA, USA) and $10 \mu \mathrm{l}$ of $10 \mathrm{pmol}$ concentration of forward and reverse primers specific for each gene and cDNA prepared in nuclease-free water. The sequences of the primers are presented in Table 1. The PCR cycling program was set to $95^{\circ} \mathrm{C}$ for $10 \mathrm{~min}$ initially and then 40 cycles of $95^{\circ} \mathrm{C}$ for $15 \mathrm{~s}$ and $60^{\circ} \mathrm{C}$ for $1 \mathrm{~min}$. Execution of melting curves was performed to ensure a single specific PCR product for each gene. Relative expression of various genes was analyzed using the $2^{-\Delta \Delta C t}$ method and was then normalized using the relative abundance of the control. GAPDH was used as a housekeeping gene based on the previous studies $(9,12,27)$. 
TABLE 2 | Effects of temperature manipulation and GABA supplementation during embryogenesis on hatchability parameters in broiler hatchlings.

\begin{tabular}{|c|c|c|c|c|c|}
\hline \multicolumn{2}{|c|}{ Treatments } & \multirow[t]{2}{*}{ Incubated eggs $(n)$} & \multirow[t]{2}{*}{ Initial egg weight (g) } & \multirow[t]{2}{*}{ Healthy chicks $(n)$} & \multirow[t]{2}{*}{ Hatchability (\%) } \\
\hline Incubation temperature & In ovo GABA & & & & \\
\hline \multirow[t]{2}{*}{ Normal temperature (T0) } & $\mathrm{O}(\mathrm{NO})$ & 62 & $59.6 \pm 0.36$ & 45 & 75.8 \\
\hline & $10 \%(N 1)$ & 63 & $59.6 \pm 0.30$ & 47 & 76.2 \\
\hline \multirow[t]{2}{*}{ Thermal manipulation (T1) } & 0 (N0) & 63 & $59.6 \pm 0.35$ & 48 & 77.8 \\
\hline & $10 \%(N 1)$ & 63 & $59.6 \pm 0.31$ & 42 & 69.8 \\
\hline
\end{tabular}

Initial egg weight data show mean \pm SEM.

TABLE 3 | Effects of temperature manipulation and GABA supplementation during embryogenesis on body weight $(\mathrm{g})$ at hatch.

\begin{tabular}{|c|c|c|}
\hline \multicolumn{2}{|c|}{ Treatments } & \multirow[t]{2}{*}{ Body weight (g) } \\
\hline Incubation temperature & In ovo GABA & \\
\hline \multirow[t]{2}{*}{ Normal temperature (T0) } & $\mathrm{O}(\mathrm{NO})$ & $37.51 \pm 0.38$ \\
\hline & $10 \%(N 1)$ & $38.63 \pm 0.43$ \\
\hline \multirow[t]{2}{*}{ Thermal manipulation (T1) } & $\mathrm{O}(\mathrm{NO})$ & $38.89 \pm 0.23$ \\
\hline & $10 \%(\mathrm{~N} 1)$ & $39.65 \pm 0.35$ \\
\hline \multicolumn{3}{|l|}{ Main effects } \\
\hline \multirow[t]{2}{*}{ Temperature } & Normal temperature (TO) & $38.08 \pm 0.29$ \\
\hline & Thermal manipulation (T1) & $39.24 \pm 0.21$ \\
\hline \multirow[t]{2}{*}{ GABA } & $\mathrm{O}(\mathrm{NO})$ & $38.22 \pm 0.23$ \\
\hline & $10 \%(N 1)$ & $39.11 \pm 0.28$ \\
\hline \multicolumn{3}{|l|}{$p$-values } \\
\hline Temperature & & 0.001 \\
\hline GABA & & 0.009 \\
\hline Temperature $\times$ GABA & & 0.621 \\
\hline
\end{tabular}

Data show mean \pm SEM.

\section{Statistical Analysis}

Data were analyzed using an IBM SPSS Statistics package 25.0 (IBM software, Chicago, IL, USA). Percent hatchability was calculated based on the number of chicks hatched to the fertile eggs following the previous studies (9). Each bird acted as an experimental unit for BW at hatch. Eight birds from each group were used to collect the organ weight. All the data were expressed as mean \pm standard error of the mean (SEM). Shapiro Wilk and Levene'stests were used to assess the normality of distribution and equality of variances. A two-way ANOVA was used taking temperature and GABA as the main effect. A Duncan's multiple range test was used if an interaction existed. Parametric differences were considered statistically significant at $p<0.05$.

\section{RESULTS}

Table 2 shows the effects of embryonic $\mathrm{T} 1$ and $\mathrm{N} 1$ on hatchability parameters. Hatching rates were similar in all groups except that the T1N1 group was 6-8\% lower than the other groups.
Both T1 and N1 significantly increased BW at hatch $(p<$ 0.01 ), but there was no significant interaction between the two (Table 3).

$\mathrm{T} 1$ and $\mathrm{N} 1$ had no significant effect on relative organ weight at hatch. However, intestine weight percent to BW had a significant interaction $(\mathrm{p}=0.028)$ and was higher in T1N1 (Table 4).

Both T1 and N1 did not have a significant effect on hepatic MDA at hatch (Figure 3). However, there was a significant interaction between temperature and GABA $(p=0.029)$, as MDA was higher in T1N1 compared to T0N0.

T1 resulted in a significant upregulation of $\operatorname{HSP70}(p=0.02)$ and HSP90 $(p=0.006)$ genes in the liver at the time of hatch (Figure 4). However, there was no significant effect for N1 or interaction between $\mathrm{T} 1$ and $\mathrm{N} 1$.

Both NOX1 and NOX4 genes were significantly increased by T1 during incubation $(p=0.001)$, but N1 or interaction was not significant at the time of hatch (Figure 5).

On the other hand, both SOD $(p=0.002)$ and CAT $(p=0.012)$ genes were significantly downregulated in the liver by T1 (Figure 6). N1 did not affect the expression of antioxidant enzyme-related genes, and no significant interaction was observed.

\section{DISCUSSION}

The current study was conducted to examine the impact of embryonic ETM with or without GABA on hatching performance and hepatic gene expression of stress- and antioxidant-related enzymes in newly hatched broiler chicks. Hatchability records show that all the treatment groups including control had hatchability ranging between 69.8 and $77.8 \%$. The reason behind the poor hatchability could be related to the age, nutrition, and environmental conditions of the breeder birds. No significant changes in hatching rates between T0N0 and T0N1 suggest that in ovo injection of GABA did not adversely affect the survivability of developing embryos. However, the hatchability of T1N1 decreased slightly compared to T0N0, T0N1, and T1N0. ETM has been considered differently as thermal conditioning $(9,28)$ or embryonic stress $(21,29)$. The logic of thermal conditioning can also be seen as the limited stress the embryo can tolerate without showing harmful effects. However, additional handling of the eggs due to in ovo GABA supplementation may have resulted in decreasing the hatchability in T1N1. Numerically 
TABLE 4 | Effects of temperature manipulation and GABA supplementation during embryogenesis on relative organ weights (percent to body weight) at hatch.

\begin{tabular}{|c|c|c|c|c|c|c|c|}
\hline \multicolumn{2}{|c|}{ Treatments } & \multirow[t]{2}{*}{ Liver (\%) } & \multirow[t]{2}{*}{ Gizzard (\%) } & \multirow[t]{2}{*}{ Proventriculus (\%) } & \multirow[t]{2}{*}{ Heart (\%) } & \multirow[t]{2}{*}{ Intestine (\%) } & \multirow[t]{2}{*}{ Yolk remnant (\%) } \\
\hline Incubation temperature & In ovo GABA & & & & & & \\
\hline \multirow[t]{2}{*}{ Normal temperature (T0) } & $\mathrm{O}(\mathrm{N} 0)$ & $2.36 \pm 0.12$ & $5.23 \pm 0.17$ & $0.94 \pm 0.08$ & $0.69 \pm 0.04$ & $4.74^{a b} \pm 0.38$ & $8.61 \pm 1.16$ \\
\hline & $10 \%(N 1)$ & $2.52 \pm 0.10$ & $4.72 \pm 0.13$ & $0.86 \pm 0.04$ & $0.76 \pm 0.03$ & $5.53^{b} \pm 0.30$ & $9.66 \pm 0.64$ \\
\hline \multirow[t]{2}{*}{ Thermal manipulation (T1) } & $\mathrm{O}(\mathrm{N} 0)$ & $2.40 \pm 0.07$ & $5.03 \pm 0.18$ & $0.77 \pm 0.04$ & $0.78 \pm 0.07$ & $4.69^{\mathrm{ab}} \pm 0.23$ & $10.07 \pm 1.16$ \\
\hline & $10 \%(N 1)$ & $2.48 \pm 0.09$ & $5.26 \pm 0.16$ & $0.88 \pm 0.05$ & $0.76 \pm 0.04$ & $4.43^{a} \pm 0.24$ & $10.37 \pm 0.46$ \\
\hline \multicolumn{8}{|l|}{ Main effects } \\
\hline \multirow[t]{2}{*}{ Temperature } & Normal temperature (TO) & $2.44 \pm 0.08$ & $4.97 \pm 0.13$ & $0.90 \pm 0.04$ & $0.73 \pm 0.03$ & $5.08 \pm 0.27$ & $9.13 \pm 0.65$ \\
\hline & Thermal manipulation (T1) & $2.44 \pm 0.06$ & $5.15 \pm 0.12$ & $0.83 \pm 0.03$ & $0.77 \pm 0.04$ & $4.56 \pm 0.17$ & $10.23 \pm 0.57$ \\
\hline \multirow[t]{2}{*}{ GABA } & $\mathrm{O}(\mathrm{NO})$ & $2.38 \pm 0.07$ & $5.13 \pm 0.12$ & $0.86 \pm 0.05$ & $0.74 \pm 0.04$ & $4.71 \pm 0.22$ & $9.29 \pm 0.82$ \\
\hline & $10 \%(N 1)$ & $2.50 \pm 0.06$ & $4.99 \pm 0.13$ & $0.87 \pm 0.03$ & $0.76 \pm 0.03$ & $4.89 \pm 0.24$ & $10.01 \pm 0.39$ \\
\hline \multicolumn{8}{|l|}{$p$-values } \\
\hline Temperature & & 0.442 & 0.223 & 0.826 & 0.143 & 0.101 & 0.078 \\
\hline GABA & & 0.54 & 0.517 & 0.922 & 0.543 & 0.402 & 0.308 \\
\hline Temperature $\times$ GABA & & 0.679 & 0.129 & 0.114 & 0.32 & 0.028 & 0.5 \\
\hline
\end{tabular}

Data show mean \pm SEM $(n=8)$.

$a, b$ : different letters indicate significant differences $(P<0.05)$.

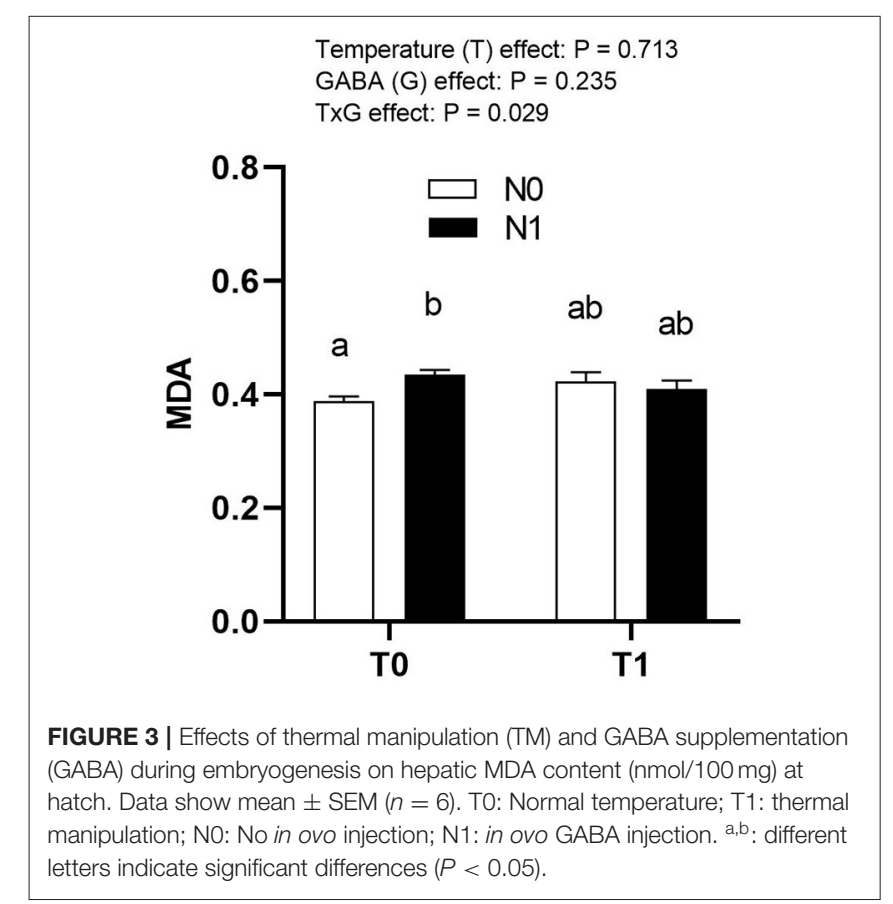

higher values of BW at hatch in the same group also indicate that weaker embryos could not survive the dual stress (T1N1).

Temperature is an important aspect of artificial incubation and has a significant effect on hatchability parameters such as BW (6). Previous studies have reported inconsistent effects of ETM on BW at hatch, either ineffective (30) or reduced BW at hatch (10). On the other hand, others have concluded that ETM increases BW at hatch $(9,28)$. The discrepancy in the results could be due to the difference in the temperature, intensity, or duration of ETM. In the current study, the increased $\mathrm{BW}$ at the hatch in $\mathrm{T} 1$ could be attributed to the development of thermotolerance arising due to daily cyclic variation of $6 \mathrm{~h}$ exposure to the higher temperature. Another possibility could be due to the survival of healthier embryos and can be correlated with the lower hatchability in T1N1. Furthermore, in ovo feeding of GABA also helped in gaining higher BW at hatch (Table 3). BW regulation involves complex processes including food consumption, digestion, nervous and endocrine systems such as thyroid and growth hormone. The effect of GABA on BW gain might be attributed to improved nutrient utilization through enhanced activity of digestive enzymes and thyroidal stimulation by growth hormone $(17,31)$.

Although the current study showed a significant interaction in hepatic MDA levels at hatch, neither ETM nor in ovo GABA supplementation significantly affected MDA levels. It appears that MDA concentrations depend on the type, severity, and duration of stress, such as heat stress. It has been previously demonstrated that MDA concentrations in serum, plasma, and tissues are much lower in chronic heat stress than in acute heat stress (4) and that there is no difference in hepatic MDA levels after receiving cyclic heat stress for 6 weeks at $32^{\circ} \mathrm{C}$ for $5 \mathrm{~h}$ (32). This suggests that MDA levels increase in the initial phase of stress, but become normal due to adaptation if the stress persists for a long time. In the present study, T0N1 had higher MDA levels than T0N0. The exact reason behind this is not clear. However, there is a possibility that in ovo feeding of GABA during embryogenesis may have resulted in increasing the MDA levels in chicks at hatch. Previous reports also suggested that in ovo supplementation of nutrients such as vitamin $\mathrm{C}$ at 17th ED increases plasma MDA linearly (33). In the present scenario, many research laboratories use mechanical processes for in ovo supplementation, which may require extra handling, create disturbance to the embryo, and possibly cause a mild 
A

Temperature $(T)$ effect: $P=0.02$

GABA $(G)$ effect: $P=0.989$

TxG effect: $P=0.881$

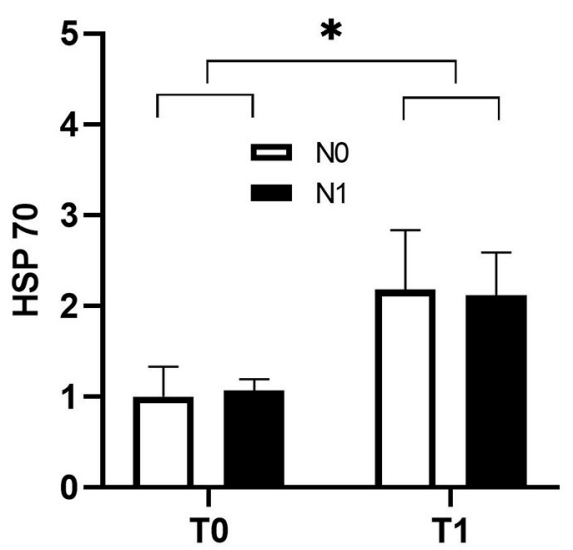

B

Temperature $(T)$ effect: $P=0.006$

GABA (G) effect: $P=0.383$

TxG effect: $P=0.843$

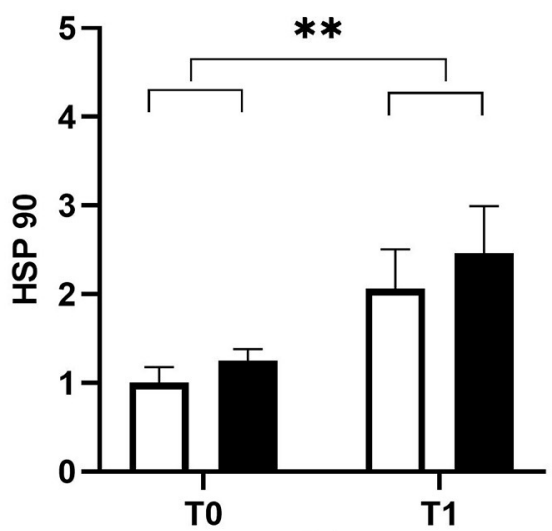

FIGURE 4 | Effects of thermal manipulation (TM) and GABA supplementation (GABA) during embryogenesis on the relative expression of (A) HSP70 and (B) HSP90 genes at hatch. Data show mean \pm SEM $(n=6)$. T0: Normal temperature; T1: thermal manipulation; NO: No in ovo injection; N1: in ovo GABA injection. "indicates significance at $P<0.05 .{ }^{* *}$ indicates significance at $P<0.01$.

A

Temperature ( $T$ ) effect: $P=0.001$

GABA (G) effect: $P=0.13$

TxG effect: $P=0.254$

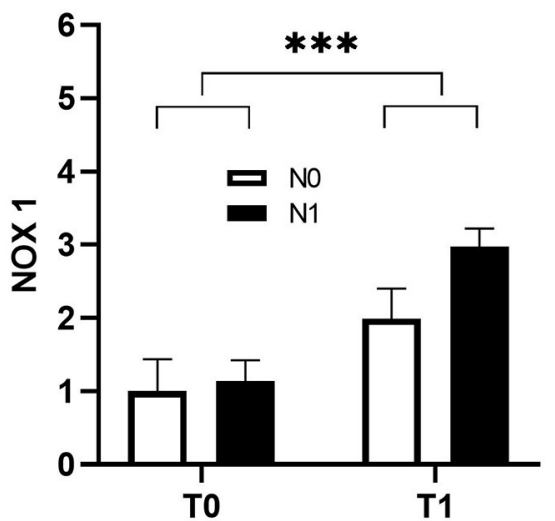

B

Temperature (T) effect: $P=0.001$

GABA (G) effect: $P=0.155$

TXG effect: $P=0.107$

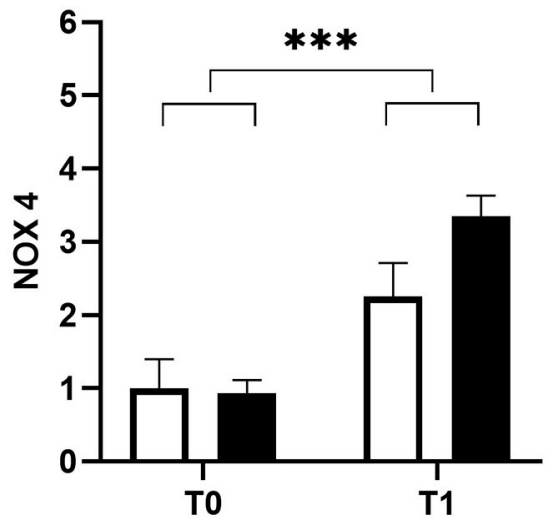

FIGURE 5 | Effects of thermal manipulation (TM) and GABA supplementation (GABA) during embryogenesis on the relative expression of (A) NOX1 and (B) NOX4 genes in liver at hatch. Data show mean \pm SEM $(n=6)$. T0: Normal temperature; T1: thermal manipulation; NO: No in ovo injection; N1: in ovo GABA injection.

indicates significance at $P<0.001$.

increase in MDA levels. The lack of information on the effects of ETM and in ovo feeding on MDA levels in various tissues requires further research to establish the mechanism behind the role of MDA regulation at hatch.

HSPs are major stress-related proteins that have been extensively studied in response to several stressors. Among them are the most explored proteins HSP70 and 90 due to their highly conserved nature (32). It has already been documented that the expression of HSP70 and 90 genes increases under acute or chronic heat stress in chickens during the rearing period $(19,34)$.
Previous studies conducted in our laboratory showed that in ovo GABA supplementation helped decrease the expression of HSP70 gene when exposed to acute heat stress $\left(38^{\circ} \mathrm{C}\right.$ for $\left.3 \mathrm{~h}\right)$ in 10-day-old chicks (12), but did not significantly affect the expression of HSP-related genes when exposed to cyclic heat stress $\left(33^{\circ} \mathrm{C}\right.$ for $6 \mathrm{~h}$ daily) from 28 to 31 days of age (25). However, scanty information is available about the expression of HSP genes in chicks at hatch after ETM and in ovo feeding. In the present study, T1 significantly increased the expression of HSP70 and 90 genes $(p<0.05)$ at hatch. These are consistent 


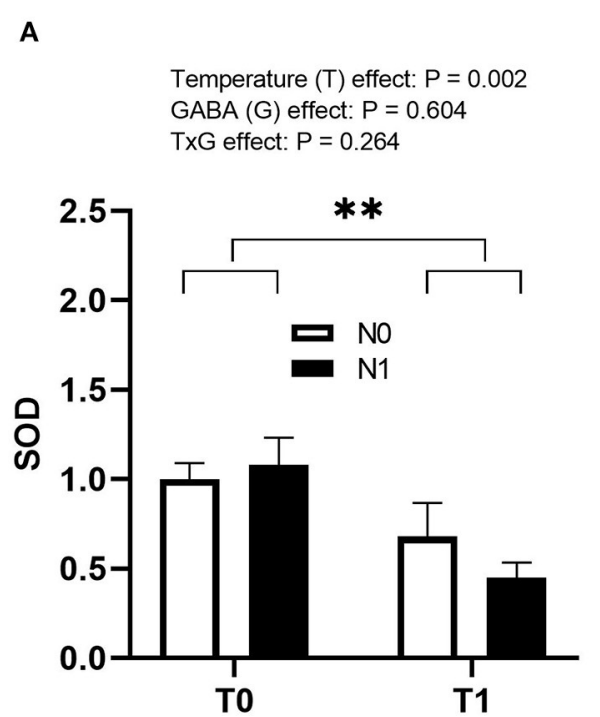

B

Temperature (T) effect: $P=0.012$

GABA (G) effect: $P=0.17$

TXG effect: $P=0.388$

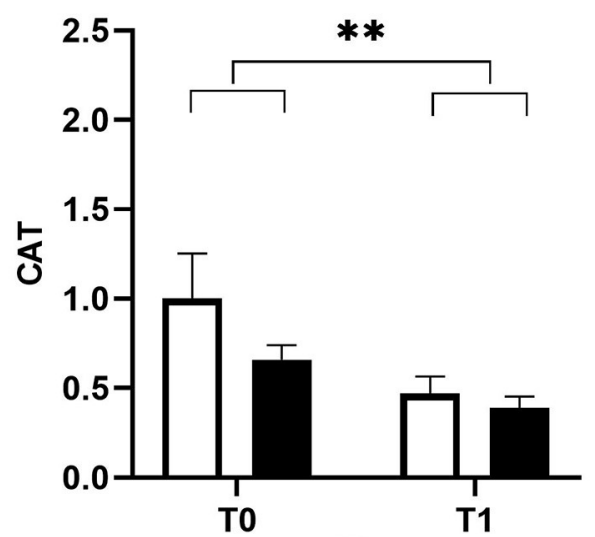

FIGURE 6 | Effects of temperature manipulation (TM) and GABA supplementation (GABA) during embryogenesis on the relative expression of (A) SOD and (B) CAT genes in liver at hatch. Data show mean \pm SEM $(n=6)$. T0: Normal temperature; T1: thermal manipulation; N0: No in ovo injection; N1: in ovo GABA injection. **indicates significance at $P<0.01$.

with previous studies in which ETM at $38.8^{\circ} \mathrm{C}$ for $6 \mathrm{~h}$ or $18 \mathrm{~h}$ a day from 10th to 18th ED had higher expression of HSP70 gene during the embryogenesis (35). Furthermore, higher HSP90 gene expression is associated with enhanced survivability of cells grown in an adverse environment (27). Thus, the increased expression of HSP-related genes after ETM may be due to its protective effects on cells. The development of tolerance against stress after ETM could be due to hormonal manifestation or behavioral adjustments (36) associated with the enhanced expression of HSP.

In the present study, the expression of NOX1 and NOX4 genes in the liver increased at hatch when embryos were incubated under high-temperature conditions, indicating higher production and accumulation of ROS in T1 chicks at hatch. NOX is a complex of different isozymes present at the surface of the membrane and acts as an oxygen sensor (37) and acts as a source of ROS production under stress conditions (38). Previous studies reported increased expression of NOX-related genes in avian cells exposed to heat stress at $41^{\circ} \mathrm{C}$ for $6 \mathrm{~h}$ (39). However, higher expression of NOX had no visible adverse effects in the current study. Furthermore, the fact that $\mathrm{T} 1$ resulted in enhanced BW along with higher NOX-related gene expression suggests that NOX accumulation at hatch may develop the ability of the chicks to withstand enhanced ROS in the later stages of life. This is evident from the previous studies where ETM showed a longlasting effect by enhancing the tolerance capacity in 28-day old Cobb broilers by decreasing the hepatic NOX4 gene expression in acute heat-stressed birds exposed at $40^{\circ} \mathrm{C}$ for $1,3,5$, and $7 \mathrm{~h}(7)$.

The antioxidant system comprises various antioxidant enzymes that activate in response to any kind of stress and prevent the oxidative damage caused by stress. SOD catalyzes the dismutation of superoxide radicals into hydrogen peroxide while CAT functions by catalyzing the breakdown of hydrogen peroxide into water molecules (40). The activity of SOD and CAT depends on the type of stress. For instance, the activity of antioxidant enzymes increases with short-term stress and decreases with long-term exposure $(41,42)$. ROS production is initiated under thermogenic conditions resulting in oxidative stress to generate excessive free radicals and superoxide $(42,43)$. In short-term stress, the antioxidant system significantly increases the activity of SOD and CAT, neutralizing free radicals and superoxide, rapidly exerting a protective effect on cells. However, in the present study, ETM was performed for $6 \mathrm{~h}$ a day from 10th to 18th ED. This can act as long-term exposure of the embryos to mild stress resulting in decreased gene expression for antioxidant enzymes (CAT and SOD) in TM chicks on the day of hatch. Long-term stress results in the accumulation of ROS due to the disruption of the antioxidant system, thus decreasing the activity of antioxidant enzymes (44). Concomitantly, T1 chicks may have the ability to tolerate higher oxidative stress later in life due to their increased ability to accumulate ROS. As a result, ETM chicks can withstand stress more conveniently (36).

The weight of most of the organs was not affected by ETM or in ovo GABA supplementation. This can be seen as a constructive approach to counter treatment (T1 or N1) presenting no harmful effects. Al Wakeel and his group reported the role of dietary GABA in enhancing feed intake and improving gut health (19). In the present study, in ovo GABA administration resulted in improving relative intestine weight and BW at hatch. To our best knowledge, this is the first study to evaluate the effect of in ovo GABA supplementation at hatch. The higher intestine weight in T0N1 suggests better gut health at hatch. This could be due to the enhanced uptake of nutrients during the last 3 days of incubation after in ovo 
GABA supplementation. In correlation, the treatment effect was also observed in terms of BW, and N1 was found to be effective in increasing the chick's BW at hatch. This confirms the role of GABA in improving growth performance due to better utilization of nutrients during incubation. Elwan and his group previously reported the role of in ovo feeding different supplements such as amino acids in improving BW at hatch (29). Furthermore, studies conducted during the rearing period have also reported higher growth and better gut health after dietary GABA supplementation in chickens exposed to stress $(13,19)$. The present study evaluated only the day of hatch, but a more pronounced effect could have been observed during the mid or after 1 week of age due to the availability of external feed and opens the window for future studies. No further effects were observed in the remaining organ weight and expression of HSP, NOX, and antioxidant enzyme-related genes in this study, suggesting no harmful effects with in ovo GABA supplementation.

In conclusion, $\mathrm{T} 1$ and $\mathrm{N} 1$ independently improved broiler BW at hatch, but T1 strongly regulated stress-related hepatic gene expression. Enhanced expression of HSP and NOX-related genes with increased BW at hatch suggests better health and viability of T1 chicks in adverse environments. GABA's effectiveness in protecting against stress might be elucidated through gut health and may have an indirect effect on the antioxidant enzyme system. Further studies are required to evaluate the effect of in ovo GABA feeding on gut health to predict its precise mechanism of action in chicks.

\section{REFERENCES}

1. Goel A, Ncho CM, Choi Y-H. Regulation of gene expression in chickens by heat stress. J Anim Sci Biotechnol. (2021) 12:11. doi: 10.1186/s40104-020-00523-5

2. Tamboli A, Goel A, Mehra M, Rokade J, Bhadauria P, Yadav A, et al. Delayed post-hatch feeding affects the performance and immunocompetence differently in male and female broiler chickens. J Appl Anim Res. (2018) 46:306-13.doi: 10.1080/09712119.2017.1299739

3. Bessei W. Impact of animal welfare on worldwide poultry production. Worlds Poult Sci J. (2018) 74:211-24. doi: 10.1017/S0043933918 000028

4. Akbarian A, Michiels J, Degroote J, Majdeddin M, Golian A, De Smet S. Association between heat stress and oxidative stress in poultry; mitochondrial dysfunction and dietary interventions with phytochemicals. J Anim Sci Biotechnol. (2016) 7:37. doi: 10.1186/s40104-01 6-0097-5

5. Habashy WS, Milfort MC, Rekaya R, Aggrey SE. Expression of genes that encode cellular oxidant/antioxidant systems are affected by heat stress. Mol Biol Rep. (2018) 45:389-94.doi: 10.1007/s11033-0184173-0

6. Hulet R, Gladys G, Hill D, Meijerhof R, El-Shiekh T. Influence of egg shell embryonic incubation temperature and broiler breeder flock age on posthatch growth performance and carcass characteristics. Poult Sci. (2007) 86:40812.doi: $10.1093 / \mathrm{ps} / 86.2 .408$

7. Al-Zghoul MB, Sukker H, Ababneh MM. Effect of thermal manipulation of broilers embryos on the response to heat-induced oxidative stress. Poult Sci. (2019) 98:991-1001.doi: 10.3382/ps/pey379

8. Goel A, Bhanja SK, Mehra M, Mandal A, Pande V. In ovo trace element supplementation enhances expression of growth genes in embryo and immune genes in post-hatch broiler chickens. J Sci Food Agric. (2016) 96:2737-45.doi: 10.1002/jsfa.7438

\section{DATA AVAILABILITY STATEMENT}

The datasets presented in this study can be found in online repositories. The names of the repository/repositories and accession number(s) can be found below: GenBank; accession numbers are included in the manuscript/ supplementary materials.

\section{ETHICS STATEMENT}

The animal study was reviewed and approved by Institutional Animal Care and Use Committee of Gyeongsang National University GNU-200916-C0058.

\section{AUTHOR CONTRIBUTIONS}

AG, CMN, and Y-HC: conceptualization and writing-review and editing. AG and CMN: methodology and data curation. AG, CMN, and C-MJ: software. AG and Y-HC: validation. AG: writing - original draft preparation. Y-HC: supervision. All authors have read and agreed to the published version of the manuscript.

\section{FUNDING}

This research was supported by the Brain Pool Program funded by the Ministry of Science and ICT through the National Research Foundation of Korea (2019H1D3A1A01071142).

9. Al-Zghoul MB, El-Bahr SM. Thermal manipulation of the broilers embryos: Expression of muscle markers genes and weights of body and internal organs during embryonic and post-hatch days. BMC Vet Res. (2019) 15:166-6. doi: 10.1186/s12917-019-1917-6

10. Zaboli GR, Rahimi S, Shariatmadari F, Torshizi MA, Baghbanzadeh A, Mehri M. Thermal manipulation during pre and post-hatch on thermotolerance of male broiler chickens exposed to chronic heat stress. Poult Sci. (2017) 96:478-85. doi: 10.3382/ps/pew344

11. Ncho CM, Jeong C, Gupta V, Goel A. The effect of gamma-aminobutyric acid supplementation on growth performances, immune responses, and blood parameters of chickens reared under stressful environment: A meta-analysis. Environ Sci Pollut Res Int. (2021) 28:45019-28. doi: 10.1007/s11356-021-13855-0

12. Ncho CM, Goel A, Jeong CM, Youssouf M, Choi YH. In ovo injection of gaba can help body weight gain at hatch, increase chick weight to egg weight ratio, and improve broiler heat resistance. Animals (Basel). (2021) 11:1364. doi: 10.3390/ani11051364

13. El-Naggar K, El-Kassas S, Abdo SE, Kirrella AAK, Al Wakeel RA. Role of gamma-aminobutyric acid in regulating feed intake in commercial broilers reared under normal and heat stress conditions. J Therm Biol. (2019) 84:16475.doi: 10.1016/j.jtherbio.2019.07.004

14. Chand N, Muhammad S, Khan RU, Alhidary IA, Rehman ZU. Ameliorative effect of synthetic hetic etic nthetic ligaba) on performance traits, antioxidant status and immune response in broiler exposed to cyclic heat stress. Environ Sci Pollut Res Int. (2016) 23:23930-35. doi: 10.1007/s11356-016-7604-2

15. Kinnersley AM, Turano FJ. Gamma aminobutyric acid (gaba) and plant responses to stress. CRC Crit Rev Plant Sci. (2000) 19:479-509. doi: 10.1080/07352680091139277

16. Tillakaratne NJ, Medina-Kauwe L, Gibson KM. Gamma-aminobutyric acid (gaba) metabolism in mammalian neural and nonneural tissues. Comp Biochem Physiol A Physiol. (1995) 112:24763.doi: 10.1016/0300-9629(95)00099-2 
17. Zhang M, Zou XT, Li H, Dong XY, Zhao W. Effect of dietary ba) metabolism in mammaliamalia in mammce, egg quality, immune activity and endocrine hormone in heat-stressed roman hens. Anim Sci J. (2012) 83:141-7. doi: 10.1111/j.1740-0929.2011.00939.x

18. Choi Y-H. Effects of $\gamma$ aminobutyric acid on mortality in laying hens during summer time. J Agri Life Sci. (2019) 53:13139.doi: 10.14397/jals.2019.53.2.131

19. Al Wakeel RA, Shukry M, Abdel AA, Mahmoud S, Saad MF. Alleviation by gamma amino butyric acid supplementation of chronic heat stress-induced degenerative changes in jejunum in commercial broiler chickens. Stress. (2017) 20:562-72. doi: 10.1080/10253890.2017.1377177

20. Goel A, Bhanja SK, Mehra M, Majumdar S, Mandal A. In ovo silver nanoparticle supplementation for improving the post-hatch immunity status of broiler chickens. Arch Anim Nutr. (2017) 71:384-94.doi: 10.1080/1745039X.2017.1349637

21. Elnesr SS, Elwan HAM, Xu QQ, Xie C, Dong XY, Zou XT. Effects of in ovo injection of sulfur-containing amino acids on heat shock protein 70 , corticosterone hormone, antioxidant indices, and lipid profile of newly hatched broiler chicks exposed to heat stress during incubation. Poult Sci. (2019) 98:2290-98. doi: 10.3382/ps/pey609

22. Williams C. In ovo vaccination and chick quality. Int Hatch Pract. (2011) 19:7c13. Available online at: http://www.positiveaction.info/pdfs/ articles/hp19.2p7.pdf

23. Pasha KV, Sadasivudu B. Intracellular content of thiol compounds, thiobarbituric acid reactive substances and gamma-glutamyl transpeptidase in rat brain during anoxia. Neurosci Lett. (1984) 46:209-14.doi: 10.1016/0304-3940(84)90443-9

24. Sabir SM, Rocha JB. Antioxidant and hepatoprotective activity of aqueous extract of solanum fastigiatum (false "jurubeba") against paracetamolinduced liver damage in mice. J Ethnopharmacol. (2008) 120:226-32. doi: 10.1016/j.jep.2008.08.017

25. Ncho C-M, Goel A, Jeong C-M, Gupta V, Choi Y-H. Effects of in ovo feeding of $\gamma$-aminobutyric acid on growth performances, plasma metabolites, and antioxidant status in broilers exposed to cyclic heat stress. Sustainability. (2021) 13:1032. doi: 10.3390/su131911032

26. Akbarian A, Michiels J, Golian A, Buyse J, Wang Y, De Smet S. Gene expression of heat shock protein 70 and antioxidant enzymes, oxidative status, and meat oxidative stability of cyclically heat-challenged finishing broilers fed origanum compactum and curcuma xanthorrhiza essential oils. Poult Sci. (2014) 93:1930ls. ndoi: 10.3382/ps.2014-03896

27. Lei L, Yu J, Bao E. Expression of heat shock protein 90 (hsp90) and transcription of its corresponding mrna in broilers exposed to high temperature. Br Poult Sci. (2009) 50:504-11. doi: 10.1080/00071660903 110851

28. Narin1 D, ErdoErd S, Tahtabitab E, Aksoy T. Effects of thermal manipulations during embryogenesis of broiler chickens on developmental stability, hatchability and chick quality. Animal. (2016) 10:1328-35. doi: $10.1017 /$ S1751731116000276

29. Elwan HAM, Elnesr SS, Xu Q, Xie C, Dong X, Zou X. Effects of in ovo methionine-cysteine injection on embryonic development, antioxidant status, igf-i and tlr4 gene expression, and jejunum histomorphometry in newly hatched broiler chicks exposed to heat stress during incubation. Animals (Basel). (2019) 9:25. doi: 10.3390/ani9010025

30. Collin A, Berri C, Tesseraud S, Rod R FE, Skiba-Cassy S, Crochet S, et al. Effects of thermal manipulation during early and late embryogenesis on thermotolerance and breast muscle characteristics in broiler chickens. Poult Sci. (2007) 86:795-800. doi: 10.1093/ps/86.5.795

31. Piqueras L, Martinez V. Peripheral gabab agonists stimulate gastric acid secretion in mice. Br J Pharmacol. (2004) 142:1038-48. doi: 10.1038/sj.bjp.0705876

32. Xie J, Tang L, Lu L, Zhang L, Xi L, Liu HC, et al. Differential expression of heat shock transcription factors and heat shock proteins after acute and chronic heat stress in laying chickens (gallus gallus). PLoS ONE. (2014) 9:e102204. doi: 10.1371/journal.pone.0102204
33. Zhang H, Elliott KEC, Durojaye OA, Fatemi SA, Schilling MW, Peebles ED. Effects of in ovo injection of l-ascorbic acid on growth performance, carcass composition, plasma antioxidant capacity, and meat quality in broiler chickens1,2,3. Poult Sci. (2019) 98:3617-25. doi: 10.3382/ps/pez173

34. Al-Zghoul MB, El-Bahr SM. Basal and dynamics mrna expression of muscular hsp108, hsp90, hsf-1 and hsf-2 in thermally manipulated broilers during embryogenesis. BMC Vet Res. (2019) 15:83-83. doi: 10.1186/s12917-019-1827-7

35. Al-Zghoul MB, Dalab AE, Ababneh MM, Jawasreh KI, Al Busadah KA, Ismail ZB. Thermal manipulation during chicken embryogenesis results in enhanced hsp70 gene expression and the acquisition of thermotolerance. Res Vet Sci. (2013) 95:502ZB. doi: 10.1016/j.rvsc.2013.05.012

36. Morita VdS, de Almeida VR, Matos JBJ, Vicentini TI, van den Brand $\mathrm{H}$, Boleli IC. Incubation temperature during fetal development influences morphophysiological characteristics and preferred ambient temperature of chicken hatchlings. PLoS ONE. (2016) 11:e0154928-e28. doi: 10.1371/journal.pone.0154928

37. Nisimoto Y, Diebold BA, Cosentino-Gomes D, Lambeth JD. Nox4: a hydrogen peroxide-generating oxygen sensor. Biochemistry. (2014) 53:5111oxidedoi: 10.1021/bi500331y

38. Burtenshaw D, Hakimjavadi R, Redmond EM, Cahill PA. Nox, reactive oxygen species and regulation of vascular cell fate. Antioxidants (Basel, Switzerland). (2017) 6:90. doi: 10.3390/antiox6040090

39. Kikusato M, Yoshida H, Furukawa K, Toyomizu M. Effect of heat stressinduced production of mitochondrial reactive oxygen species on nadph oxidase and heme oxygenase- 1 mrna levels in avian muscle cells. J Therm Biol. (2015) 52:8-13. doi: 10.1016/j.jtherbio.2015.04.005

40. Halliwell B. Reactive species and antioxidants. Redox biology is a fundamental theme of aerobic life. Plant Physiol. (2006) 141:312-22. doi: 10.1104/pp.106.077073

41. Sahin K, Orhan C, Tuzcu M, Ali S, Sahin N, Hayirli A. Epigallocatechin-3gallate prevents lipid peroxidation and enhances antioxidant defense system via modulating hepatic nuclear transcription factors in heat-stressed quails. Poult Sci. (2010) 89:2251-8. doi: 10.3382/ps.2010-00749

42. Yang L, Tan G-Y, Fu Y-Q, Feng J-H, Zhang M-H. Effects of acute heat stress and subsequent stress removal on function of hepatic mitochondrial respiration, ros production and lipid peroxidation in broiler chickens. Comp BiochemPhysiol C Toxicol Pharmacol. (2010) 151:204-08. doi: 10.1016/j.cbpc.2009.10.010

43. Palmer HJ, Paulson KE. Reactive oxygen species and antioxidants in signal transduction and gene expression. Nutr Rev. (1997) 55:353-61. doi: 10.1111/j.1753-4887.1997.tb01561.x

44. Hu R, He Y, Arowolo MA, Wu S, He J. Polyphenols as potential attenuators of heat stress in poultry production. Antioxidants (Basel, Switzerland). (2019) 8:67. doi: $10.3390 /$ antiox 8030067

Conflict of Interest: The authors declare that the research was conducted in the absence of any commercial or financial relationships that could be construed as a potential conflict of interest.

Publisher's Note: All claims expressed in this article are solely those of the authors and do not necessarily represent those of their affiliated organizations, or those of the publisher, the editors and the reviewers. Any product that may be evaluated in this article, or claim that may be made by its manufacturer, is not guaranteed or endorsed by the publisher.

Copyright (c) 2022 Goel, Ncho, Jeong and Choi. This is an open-access article distributed under the terms of the Creative Commons Attribution License (CC BY). The use, distribution or reproduction in other forums is permitted, provided the original author(s) and the copyright owner(s) are credited and that the original publication in this journal is cited, in accordance with accepted academic practice. No use, distribution or reproduction is permitted which does not comply with these terms. 